At the end of every single session the animal handler had to fill in three evaluation sheets:

- one for patients

- one for their relatives (if present)

- one for healthcare professionals.

\section{P-48 "SINGING IN THE CHOIR WOULDN'T DO US ANY HARM": EXPLORING A UNIQUE PARTNERSHIP BETWEEN A FREELANCE MUSIC THERAPIST, A LEADING NATIONAL LUNG CHARITY AND AN ADULT HOSPICE}

1,2,3,4 Anna Ludwig. 'Harperhall Music Therapy, Biggar, UK; ${ }^{2}$ Kilbryde Hospice, East Kilbride; ${ }^{3}$ Team Jak Foundation, Livingston; ${ }^{4}$ Lady Home Hospital, Douglas

10.1136/bmjspcare-2016-001245.72

In 2015 a national lung charity funded a 12-week pilot project in 10 UK locations called "Singing for Lung Health". Giving a brief introduction to music therapy in an adult hospice setting, this paper will then explore how the music therapist worked in collaboration with the lung charity and the hospice to develop and run the choir after the initial 12 weeks of funding and will include what the potential benefits of singing in a choir can be.

Aims of the choir

- To evaluate and monitor changes in breathing, confidence and general health and well-being using questionnaires provided initially by the lung charity and now in development with the hospice and the music therapist

- To use and develop vocal and breathing techniques, originally geared towards those with lung conditions, for use with a wider client group including those with life-limiting conditions

- To maintain and develop the choir to include hospice patients, carers, staff, volunteers and members of the public

This work in progress is

- Bringing people together at the hospice from all walks of like, with or without a life-limiting condition

- A partnership with the choir, the hospice and the music therapist which includes writing and performing a song together to promote the work of the hospice (this will be shared during the presentation)

- Highlighting the potential health and well-being benefits of singing in a choir (including physical, mental, emotional and social benefits)

- Promoting the work of the hospice to the wider community

To conclude, the author aims to share this creative work in progress in order to highlight the benefits of singing in a choir, the unique collaboration between the music therapist, hospice and lung charity and thoughts around how this work may be evaluated in the future to ensure its success and continuation.

\section{P-49 POPPIES}

Nicci Williamson, Karen McPhail, Stuart Cartlidge. Douglas Macmillan Hospice, Stoke-onTrent, UK

\subsection{6/bmjspcare-2016-001245.73}

Diversional therapy is a tool used to help patients express emotions in a different way. Activities are devised with a worthwhile outcome and all patients, of all abilities, can participate. It encourages communication, expression, comradeship and reminiscence thus giving purpose and meaning for patients in our care.

One such project was to create our own 'Tower of London' display of poppies, but on a smaller scale. Poppies were to be made out of plastic bottle bottoms, painted by hand in red and black.

As the idea took hold, so the project grew. Patients formed their own 'industrial line' with some cutting, others painting and the rest assembling. The goal was for 3500 poppies. The design was drawn by an ex-draughtsman patient using his professional skills. It involved an 8 foot cross covered in poppies with a cascade of flowers to two giant poppies on the ground. The whole display measured approximately 50 metres in length and five metres in width and ran from the Spiritual Space to the Day Therapy Unit.

Patients, carers, visitors, staff and local schools 'worked' to create poppies. A growth chart recorded the number of poppies made with the target being 3500 .

Local radio and newspapers appealed for bottles and the project took on a life of its own. It culminated in a service of Remembrance on the 11 November 2015 at the hospice. The service was attended by patients, carers, visitors, staff, local schools, dignitaries from the local community and British Legion. An ex-serviceman patient read the 'Ode of Remembrance'. A young schoolboy played the bugle 'Last Post' to finish.

Patients participated with enthusiasm and motivation, staff felt the strength of working as a team. Collaborative working took the hospice into the local community. The Hospice profile was raised in the media. Conversation and laughter flowed and continues to this day.

\section{P-50 ROYAL TRINITY HOSPICE 'WELCOMES' THE WELLBEING PROGRAMME WITH SUCCESS}

${ }^{1}$ Moira O'Connell, ${ }^{1,2}$ Sian Evans. ${ }^{1}$ Royal Trinity Hospice, London, UK; ${ }^{2}$ Macmillan Cancer Support

\subsection{6/bmjspcare-2016-001245.74}

Background Prior to the launch of the Wellbeing Programme an outpatient service evaluation was completed in 2014, with the following needs identified:

- Peer support for patients, carers and families

- Earlier intervention for patients/carers and the wider health economy for people with palliative care conditions

- A model for day/outpatient services, based on a therapeutic approach to rehabilitation and critically, self-management.

\section{Aim}

- To widen the breadth of support and care we provide to our patients to include Wellbeing Programmes through the introduction of peer and carer support sessions

- Ensure patients, families and carers feel supported in relation to their anxieties and practical matters about their palliative journey

- To start the new programme within six months of posts being in place

- To build partnerships with other organisations collaborating and practicing seamless communication links to ensure patient needs are addressed in a timely manner

- To further embed Royal Trinity Hospice as a provider of specialist palliative care services within its community. 
Method To introduce 'The Macmillan Wellbeing Programme' funded by Macmillan Cancer Support, to develop, coordinate and deliver, over two years, a range of wellbeing and psychosocial programmes, giving great peer support, empowering better management of health and facilitating earlier access to hospice services. Impact is measured through an increase in the number of outpatients, referrals from non-Trinity professionals and outpatient volunteers.

Results Number of patients seen: 2013/2014: 286 2015/2016: 319 Target increase: 3\% Actual increase: 12\%

Referrals from non-Trinity professionals: 2013/2014: 108 2015/2016: 263 Target increase: 20\% Actual increase: 144\%

Number of outpatient volunteers: 2013/2014: 28 2015/2016: 39 Target increase: 20\% Actual increase: 39\%

Conclusion Launched in September 2015, the Wellbeing Programme has exponentially grown over the past year significantly exceeding the targets given. The introduction of the programme has results in establishing a community within Royal Trinity Hospice for patients, carers and families to become part of and feel supported through their individual journeys.

\section{P-51 THE LIVING WELL GROUP: ENCOURAGING WELLBEING THROUGH SELF-MANAGEMENT AND SOCIALISATION}

Chenise Moyston, Barbara Littlechild. Royal Trinity Hospice, London, UK

\subsection{6/bmjspcare-2016-001245.75}

Background Within the development of out-patient services in collaboration with the Macmillan Wellbeing programme at the hospice, the occupational therapy department established and assisted in the development of a Living Well Group.

Self-management of symptoms can allow patients and carers effected by life-limiting illness autonomy and improved quality of life and group sessions can facilitate socialisation and peer support. Aims

- Provide a multidisciplinary programme teaching selfmanagement techniques for a wide range of symptoms

- Provide a space for socialisation and peer support

- Identify potential need for referral to specialist services

- Include outpatients, carers and inpatients

- Improve general wellbeing.

Method A seven-week rolling programme was designed, each week covers a different topic and is led by a different professional, and a volunteer is also present for additional support.

\begin{tabular}{ll}
\hline Subject of Session & Facilitated by \\
\hline Fatigue and sleep & Occupational therapy \\
Anxiety and stress & Patient and Family Support Team \\
Breathlessness & Physiotherapy \\
Open nurse session & Outpatient nurse \\
Complementary therapy & Complementary therapy \\
Spiritual care & Spiritual Care Lead \\
Open session and benefits advice & Occupational Therapy and Welfare Advisor \\
\hline
\end{tabular}

Each session lasts 1.5 hours including; one hour focusing on teaching and advice for self-management related to the subject, encouraging active participation, discussion and peer support. 30 minutes break when socialisation between participants is encour- aged, cake and refreshments funded by Macmillan further encourage a relaxed environment.

Results Three cycles of the group are complete with a total of 25 attendees; 19 outpatients, three carers and three inpatients. Using an informal referral process has made it easy for external services to refer into the group thus broadening outreach and supporting partnerships with our communities.

A patient satisfaction survey was completed at the end of each session which provided the following feedback:

\begin{tabular}{ll}
\hline User comments & Potential wider context \\
\hline "I find it difficult to trust...But I have & Improved quality of life and wellbeing, \\
formed valuable friendships due to this & peer support and socialisation \\
group" & Better self-management of symptoms, \\
"I always take one thing away with & interactive learning, improved quality of \\
me" & life and wellbeing \\
"I wish the group was longer" & Enjoyment and improved quality of life, \\
"I enjoy listening to others" & further involvement with outpatient \\
& services. \\
& Peer support, shared learning, \\
& socialisation \\
\hline
\end{tabular}

Following on from the group four were then referred to other services where they could access more detailed and specialist support.

Conclusion The next cycle will commence July 2016, with the addition of dietary advice session. With ongoing advertising and partnerships with our local communities there is potential for the group to grow and remain a feature of the hospice outpatient service, it is clear that self-management techniques, socialisation and peer support are valued by participants.

With ongoing evidence supporting self-management of symptoms in palliative care and socialisation for improved wellbeing, groups such as the 'Living Well Group' are significantly relevant and could further support hospice care.

\section{P-52 OUR LIVING WALL - ART, FUN, STORIES AND FEELING CONNECTED}

Sabine Schwaebisch. Helen and Douglas House, Oxford, UK

\subsection{6/bmjspcare-2016-001245.76}

Our Living Wall (OLW) is a communal art wall at the heart of a children's hospice. We wanted to see whether a wall like this could impact on the happiness of children who visit.

We created a huge wall made of large removable jigsaw pieces. Children and their families, with staff help, take a piece and make it their own, through paint, stickers, images, etc., before putting it back on the wall. All pieces are photographed; next to the wall and online is a rolling exhibition of past pieces. When the wall is full, the child/family can take their piece home or it can be recycled.

We are acutely aware of the challenges faced by these children (limited chances to play, lack of control, low self-esteem, limited social connexion) and wanted to respond to these in a fun and creative way. The intention is for OLW to be as inclusive as possible, accessible to all children (0-18) with life-limiting conditions, regardless of age, ability, illness or background.

Our Living Wall has been up and running since April 2015, with over 100 pieces created so far. 